\title{
Erratum to "Research on China Academic Social Sciences and Humanities Library" [Voice of the Publisher 3 (2020) 110-115]
}

\author{
Lei Yi \\ Information Quality Institute, Beijing University of Chemical Technology, Beijing, China \\ Email: 81058259@qq.com
}

How to cite this paper: Yi, L. (2021). Erratum to "Research on China Academic Social Sciences and Humanities Library" [Voice of the Publisher 3 (2020) 110-115]. Voice of the Publisher, 7, 117-122. https://doi.org/10.4236/vp.2021.74010

Received: September 29, 2021

Accepted: October 26, 2021

Published: October 29, 2021

Copyright ( 2021 by author(s) and Scientific Research Publishing Inc. This work is licensed under the Creative Commons Attribution International License (CC BY 4.0).

http://creativecommons.org/licenses/by/4.0/

\section{(c) (i) Open Access}

The original online version of this article (Yi, L. (2020). Research on China Academic Social Sciences and Humanities Library. Voice of the Publisher, 6, 110-115. https://doi.org/10.4236/vp.2020.63012) unfortunately contains some mistakes. The author wishes to correct the errors.

\section{Introduction}

China Academic Social Sciences and Humanities Library (CASHL) is a platform that provides foreign language literature and related information services (IS) for the teaching and research of Chinese philosophy and social sciences (PSS) under the leadership of the Chinese Ministry of Education (CME) (CASHL, 2020). In 2002, in order to develop Chinese PSS, the CME began preparations for CASH (Liang et al., 2015). In 2004, CASHL officially began to serve readers with interlibrary loan (ILL) and document delivery (DD). CASHL has established a complete "co-construction and sharing" mechanism covering China, and it currently has 881 member libraries and more than 136,000 individual registered users (CASHL, 2020). It can be said that CASHL has established China's largest and most comprehensive humanities and social science (HSS) document guarantee system (Yi, 2020).

\section{Development Ideas}

CASHL takes the "national HSS information resource platform" as its construction goal, and systematically introduces foreign HSS books, periodicals and electronic resources (ER) by organizing China's higher education libraries with advantages in disciplines, resources and services (CASHL, 2020). It uses modern service methods (including New Internet Platforms, Big Data, Human Intelligence, 5G, Blockchain, Internet of Things, etc.), to integrate research results in 
the HSS of Chinese universities, serves China's development strategy, and provides comprehensive documentation and information resources for the teaching and research of HSS (CASHL, 2020).

In terms of resource construction, CASHL follows the principle of overall arrangement and efficiency, by building a three-level system of National Center (NC), regional center (RC) and discipline center (DC), which achieves the cooperation of literature collection and service, and builds the highest level, most comprehensive and most sustainable document resources center in the field of HSS in China (CASHL, 2020).

In terms of service, CASHL has established a centralized network service system (SSM), which reveals the printed periodicals, ER, literature books and large-scale special collections collected by each member library, and provides comprehensive literature IS for the universities and PSS research institutions in China (CASHL, 2020).

\section{Resources}

CASHL provides unified retrieval of printed books and e-books for university readers across the country, and provides sharing services (SSS) in the form of ILL and DD. Its printed books cover nearly 3 million kinds of books from more than 70 university libraries (UL) and Shanghai libraries. Its e-books cover nearly 2 million kinds of 17 UL. Disciplines include literature, art, history, archaeology, philosophy, politics, military, economy, law, education, sociology, journalism and communication, management, psychology, library and information philology, linguistics, regional studies, etc. (CASHL, B.R., 2020).

CASHL provides unified retrieval of printed and electronic journals (EJ) for university readers across the country, and provides document SSS through ILL and original text transmission. Its printed periodicals cover nearly 50,000 kinds of journals from 17 domestic UL, Shanghai Library and Chinese Academy of Social Sciences Library (CASSL). Its EJ cover nearly 140,000 kinds of 17 UL (CASHL, J.R., 2020).

CASHL integrates more than 900 databases of HSS, covering all disciplines of HSS, including literature, art, history, archaeology, philosophy, politics, military, economy, law, pedagogy, sociology, journalism and communication, management, psychology, linguistics, as well as various cross disciplines. There are more than 20 types of documents, such as books, periodicals, dissertations, audio-visual, music score, map, etc. (CASHL, D.R., 2020).

CASHL also has large-scale special collection of literature. Its carrier types include large books, journal bound books, microfilm materials, picture materials, etc. (CASHL, L.S., 2020). At present, 223 kinds have been introduced and are increasing every year (Wei et al., 2020). At the same time, CASHL and the CASSL carry out strategic cooperation to jointly provide literature support services (Chen, 2013). Through CASHL, readers can access the literature resources (LR) in the national academic journal database of PSS. The database is an open 
access Chinese Full-text Database supported by the National Social Science Fund, constructed by the Chinese Academy of SS and developed and maintained by the investigation and data information center of the CASSL. It includes more than 1000 excellent academic journals, more than 4.85 million papers, more than 1.01 million scholars and 21,000 research institutions, 200 key journals supported by the National Social Science Foundation, more than 80 journals sponsored by the Chinese Academy of SS, and more than 500 core journals included in the three evaluation systems (China Academy of SS, Peking University and Nanjing University). There are more than 500 periodicals, the earliest of which dates back to 1921 (CASHL, N.P., 2020).

CASHL users can also search through the homepage and send out application for DD, so as to obtain the periodical DD service provided by the member library during the period of the Republic of China (CASHL, C.R., 2020). The "catalogue of the Republic of China" of CASHL includes the collections of seven libraries of Fudan University, Xiamen University, East China Normal University, Fujian Normal University, Shanghai University, Shaoxing University of Arts and science, and the Life Science Library of Shanghai Life Science Information Center, Chinese Academy of Sciences (CASHL, C.R., 2020). It covers more than 7000 journals of the Republic of China, covering a wide range of subjects, including literature, language, SS, historical geography, education, economy, politics, law, philosophy, religion, military, sports, art, library and information, journalism, natural science, mathematics and chemistry, medicine and health, agriculture, industry, transportation, etc. (Zhang \& Chen, 2015; CASHL, C.R., 2020).

Through CASHL, readers can search the literature of "University Ancient Literature Resource Database", which is led by Peking University and jointly constructed by 27 universities in the United Nations, including the Chinese University of Hong Kong and the University of Macau, as well as the University of British Columbia in Canada, the East Asian Library of University of Washington, and the Yanjing Library of Harvard University (CASHL, C.A., 2020). The main construction of the resource database (RD) was completed in April 2012. At present, it has nearly 700,000 ancient book bibliographic metadata, 200,000 Book shadow images and nearly 100,000 e-books (CASHL, C.A., 2020).

\section{Management and Service System}

CASHL management and SSM include two national centers, seven regional centers and eight discipline centers. CASHL NC is located in Peking University and Fudan University, which is responsible for the overall planning, construction and service of resources. It collects printed periodicals and ER, provides the collection data of foreign HSS journals, maintains the local DD SSM, and provides training, publicity, literature retrieval and original text supply services for the whole country and makes relevant evaluation (CASHL, C.C., 2020). CASHL RC is located in Wuhan University, Jilin University, Sun Yat-sen University, Nanj- 
ing University, Sichuan University, Beijing Normal University and Lanzhou University, which assists the NC in the overall planning, construction and service of resources, collects printed periodicals and ER, provides the collection data of foreign humanities and SS periodicals, maintains local DD SSM, and carries out training, publicity, literature retrieval and original text supply (CASHL, C.C., 2020). CASHL DC is located in Northeast Normal University, East China Normal University, Nankai University, Shandong University, Tsinghua University, Xiamen University, Zhejiang University and Renmin University of China, which plans and collects ER and characteristic resources according to the discipline characteristics, provides the collection data of foreign humanities and SS journals, maintains local DD SSM, and cooperates with national and regional centers to carry out training, publicity and original text provision services, and carries out relevant evaluation (CASHL, C.C., 2020). Table 1 shows the characteristic disciplines of each subject center of CASHL.

Readers can obtain required LR through CASHL literature delivery. CASHL $\mathrm{DD}$ is a non-returnable document provision service, which copies and delivers foreign language journal articles, book chapters, microform materials and other documents collected by each member library for users (Yang, 2008). CASHL DD methods mainly include two methods: Email and online DD system (FTP). Table 2 shows the top 5 CASHL original text delivery requests in 2018 (CASHL, U.R., 2018). At the same time, readers can also borrow foreign language books in

Table 1. Characteristic disciplines of CASHL discipline center (CASHL, C.C., 2020).

\begin{tabular}{cc}
\hline Subject Center & Featured subjects \\
\hline Northeast Normal University Library & Basic Education and World History \\
East China Normal University Library & Human Geography, Principles of Education \\
Nankai University Library & European and American Studies \\
Shandong University Library & Literature and Art, Ancient Chinese Philosophy \\
Tsinghua University Library & management \\
Xiamen University Library & Taiwan Studies, Southeast Asian Studies \\
Zhejiang University Library & Applied Psychology, Linguistics \\
Library of Renmin University of China & Economics and Law \\
\hline
\end{tabular}

Table 2. CASHL member usage ranking (TOP 5) in 2018 (CASHL, U.R., 2018).

\begin{tabular}{cc} 
Member hall name & $\begin{array}{c}\text { Number of requests issued } \\
\text { (items) }\end{array}$ \\
\hline Yunnan Normal University Library & 5210 \\
Northeast Normal University Humanities College Library & 2894 \\
Zhengzhou University Library & 1806 \\
Nanjing University Library & 1172 \\
Wuhan University Library & 1096
\end{tabular}


Table 3. CASHL member usage ranking (TOP 5) in 2019 (CASHL, N.L., 2020).

\begin{tabular}{cc}
\hline Member hall name & $\begin{array}{c}\text { Number of requests issued } \\
\text { (items) }\end{array}$ \\
\hline Yunnan Normal University Library & 5940 \\
Northeast Normal University Humanities College Library & 1685 \\
Nanjing University Library & 1215 \\
Wuhan University Library & 1135 \\
Yichun College Library & 1061 \\
\hline
\end{tabular}

the collection of each member library and foreign language books in the collection of Shanghai Library through CASHL ILL (Niu et al., 2016).

So far, CASHL has provided services for more than 24,600 core HSS and important journals, more than 2 million printed books, and 12 electronic RD. It has provided a total of nearly 22 million literature services (LS), including manual LS (CASHL, 2020). It has exceeded 1.3 million, and the average document satisfaction rate is about $96.29 \%$ (CASHL, 2020). In addition, CASHL also provides databases such as the "University HSS Foreign Language Periodical Catalogue Database" and "University HSS Foreign Language Books Joint Catalogue" and other databases, providing database retrieval, browsing and consulting services (CASHL, 2020). Table 3 shows the top 5 CASHL original text delivery requests in 2019 (CASHL, N.L., 2020).

\section{Conclusion}

In different historical periods, CASHL has undertaken different historical tasks, from the early construction of a master and doctoral base to the development of philosophy and social science missions, to the current needs of the construction of new think tanks. CASHL has played a certain role in promoting the prosperity and development of the PSS in China. The CASHL project has made significant contributions to the personnel training, education and teaching, and academic research of Chinese higher education. Through the study of CASHL, we can see how Chinese academic libraries share resources in the field of humanities and social sciences.

\section{Acknowledgements}

This short introductory text about CASHL for international students of Beijing University of Chemical Technology, whose information mainly comes from the CASHL official website (COW), here I would like to thank my CASHL colleagues, with their strong support that I can successfully complete the various publicity and promotion jobs of CASHL every year. If readers want to know more about CASHL, they can log in to the COW for in-depth reading.

\section{Conflicts of Interest}

The author declares no conflicts of interest regarding the publication of this paper. 


\section{References}

CASHL, B.R. (2020). CASHL's Book Resources. http://www.cashl.edu.cn/node/5

CASHL, C.A. (2020). CASHL College Ancient Document Resources. http://www.cashl.edu.cn/index.php/node/18

CASHL, C.C. (2020). CASHL Central Library. http://www.cashl.edu.cn/node/47

CASHL, C.R. (2020). CASHL Catalogue of the Republic of China. http://www.cashl.edu.cn/node/13

CASHL, D.R. (2020). CASHL's Database Resources. http://www.cashl.edu.cn/alldatabase

CASHL, J.R. (2020). CASHL Journal Resources. http://www.cashl.edu.cn/node/6

CASHL, L.S. (2020). Introduction of CASHL's Large-Scale Special Collection. http://www.cashl.edu.cn/index.php/node/2967

CASHL, N.L. (2020). CASHL Newsletter (Issue 1, 2020). http://www.cashl.edu.cn/index.php/ctx

CASHL, N.P. (2020). National Philosophy and Social Sciences Academic Journal Database. http://www.cashl.edu.cn/node/2967

CASHL, U.R. (2018). CASHL Usage Ranking. http://www.cashl.edu.cn/index.php/node/34

CASHL (2020). About CASHL. http://www.cashl.edu.cn/node/45

Chen, T. (2013). Interpreting the Cooperation of CASHL with Chinese Academy of Social Science. Journal of Academic Libraries, 31, 31-34.

Liang, N. Y., Liu, S. Q., Li, X. D., \& Wang, J. J. (2015). Study on the Situation and Development of CASHL. Journal of Academic Libraries, 33, 72-78.

Niu, A. J., Yang, X. P., \& Qing, W. (2016). Comparative Study on OCLC World Share ILL and CASHL ILL. Journal of Academic Libraries, 34, 63-68.

Wei, Q. H., Sun, L., \& Hu, W. J. (2020). Research on Digital Construction of Special Collections of University Libraries: A Case Study of CASHL. Journal of Academic Library and Information Science, 38, 81-86.

Yang, J. H. (2008). The Analysis and Comparison of the Relationships between the Two Document Delivery Systems of CALIS and CASHL. Library Development, No. 11, 61-66.

Yi, L. (2020). Research on the University Library Alliance of China. Open Access Library Journal, 7, e6672. https://doi.org/10.4236/oalib.1106672

Zhang, C. M., \& Chen, Y. Y. (2015). CASHL's Document Delivery Service Demand Analysis and Countermeasure Research in Republic of China. Research on Library \& Information Work of Shanghai Colleges \& University, 25, 35-42. 